\title{
Valerian treatment during the postpartum period alters breast milk composition and impairs long-term memory in female rat offspring
}

\author{
D.P. Carvalho ${ }^{1 \oplus \bowtie}$, V.M. Peters ${ }^{1 \oplus}$, A.F. Dias ${ }^{1 \oplus}$, S.C.P.L. Dutra ${ }^{2 \odot}$, and M.O. Guerra ${ }^{1 \oplus}$ \\ ${ }^{1}$ Centro de Biologia da Reprodução, Universidade Federal de Juiz de Fora, Juíz de Fora, MG, Brasil \\ ${ }^{2}$ Departamento de Nutrição, Universidade Federal de Juiz de Fora, Juíz de Fora, MG, Brasil
}

\begin{abstract}
Maternal anxiety symptoms in the perinatal period might have long-term health effects on both the mother and the developing child. Valerian is a phytotherapeutic agent that is widely used for the treatment of anxiety. This study investigated the effects of valerian treatment in postpartum rats on maternal care, toxicity, and milk composition. Postnatal development, memory, and

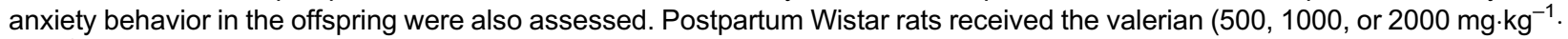
day $^{-1}$ ) by oral gavage. Clinical and biochemical toxicity was evaluated with commercial kits. Maternal behavior was observed daily. Milk composition was analyzed by colorimetric methods. Physical and neuromotor tests were used to analyze postnatal development. Anxiolytic activity was assessed by the elevated plus maze, and memory was evaluated by the step-down inhibitory avoidance task. Maternal toxicity and care behavior were not altered by the treatment, while only the highest dose promoted a significant increase of lactose, and the doses 1000 and $2000 \mathrm{mg} \cdot \mathrm{kg}^{-1}$. $\mathrm{day}^{-1}$ promoted a reduction of protein contents in milk. Postnatal development was similar in all offspring. Adult offspring did not display altered anxiety behavior, while long-term memory was impaired in the female adult offspring by maternal treatment with $1000 \mathrm{mg} \cdot \mathrm{kg}^{-1} \cdot \mathrm{day}^{-1}$. These results suggested that high doses of valerian had significant effects on important maternal milk components and can cause long-term alterations of offspring memory; thus, treatment with high doses of valerian is not safe for breastfeeding Wistar rat mothers.
\end{abstract}

Key words: Anxiety; Postpartum disorders; Mental health; Valeriana officinalis; Lactation

\section{Introduction}

The perinatal period is complex and vulnerable. Challenges during pregnancy can cause the development of postpartum psychiatric disorders (PPDs) (1). PPDs, such as depression and anxiety, are relatively common and are described as emotional conditions with frequent anxiety symptoms and episodes of low attention span, tiredness, muscle tension, and excitement (2).

Women with psychiatric disorders during the perinatal period are at increased risk for adverse maternal and child outcomes (3). Environmental changes during the periods of enhanced plasticity (intrauterine life and/or lactation) can induce disorders in the offspring. This phenomenon is known as programming or developmental plasticity $(4,5)$.

Mental health assessment and intervention are important components of routine perinatal care (3). Thus, drug treatment is a possible intervention to reduce postpartum anxiety and its consequences on the newborn. Complementary and alternative therapies are used more often than conventional therapies by people with self-defined anxiety attacks and severe depression (6). Valerian, an extract of the Valeriana officinalis root, is one of the most popular herbal medications for insomnia and anxiety (7). Valerian contains sesquiterpenes, iridoids (valepotriates), alkaloids, free amino acids, and other chemical components (8). Valerenic acid, an essential oil, is considered the main active valerian substance that inhibits GABAase enzyme in the synaptic cleft to increase gamma-aminobutyric acid (GABA) neurotransmitter availability in the cleft and enhance its inhibitory effect on the central nervous system (CNS) (9).

The use of several extracts of Valeriana officinalis can lead to increased anxiolytic and antidepressant activity in rats (10). Campos et al. (11) evaluated the effects of valerian treatment on rats during pregnancy and observed no alterations in postpartum development or in adult anxiety levels in the offspring. Studies indicate that valerian has antioxidant and neuroprotective effects $(12,13)$. The extract of Valeriana officinalis modulates 
brain neurotransmitters $(14,15)$. A single oral dose of valerian extract modulates intracortical facilitatory circuits (16).

Considering that drug metabolism and excretion are limited in newborns and that the blood-brain barrier is in development, xenobiotic consumption via breastfeeding can lead to metabolite accumulation in newborns (17). Xenobiotics can lead to biological, behavioral, and developmental alterations in childhood and adulthood, which justifies the studies focusing on phytotherapeutic treatment during lactation (18).

In this context, the present study used Wistar rats to investigate the toxicity, milk composition, and maternal behavioral alterations caused by valerian treatment during lactation. Furthermore, possible effects on the physical and neuromotor development of the offspring and on longterm memory and anxiety behavior in adulthood were evaluated.

\section{Material and Methods}

\section{Animals}

The animal experiments were approved by the Ethics Committee on Animal Use of the Federal University of Juiz de Fora (protocol No. 002/2017). Seventy-five female Wistar rats (60 days) were mated with male Wistar adult rats. Animals were kept in polypropylene cages $(49 \times 34 \times 16 \mathrm{~cm})$ in ventilated cabinets (ALESCO ${ }^{\circledR}$, Brazil) with controlled air flow and regulated temperature $\left(22 \pm 2^{\circ} \mathrm{C}\right)$; the animals had free access to food and filtered water and were housed at a 12-h light/dark cycle.

\section{Treatment and experimental design}

The extract was obtained from a commercial powder of Valeriana officinalis, Florien ${ }^{\circledR}$ (Brazil); a physicochemical quality analysis was carried out, and the valerenic acid concentration was $0.82 \%$. The valerenic acid was calculated by the method of Al-Majed (2006) considering the daily recommended dose for an adult human $(3060 \mathrm{mg}$ ) and adjusting to rodent metabolism (six-fold higher than the calculated value for humans) (19), and the preparations contained aqueous extract with $20 \%$ double-distilled white glycerol (Galena ${ }^{\circledR}$, Brazil).

On postnatal day (PD) 2, lactating rats were randomly assigned to each of the following groups ( $n=15$ per group): Control (1 $\mathrm{mL}$ of distilled water), Vehicle (1 $\mathrm{mL}$ of distilled water $+20 \%$ glycerol), and 3 treatment groups T-500 (valerian, $500 \mathrm{mg} \cdot \mathrm{kg}^{-1} \cdot \mathrm{day}^{-1}$ ), T-1000 (valerian, $1000 \mathrm{mg}$. $\mathrm{kg}^{-1} \cdot \mathrm{day}^{-1}$ ), and T-2000 (valerian, $2000 \mathrm{mg} \cdot \mathrm{kg}^{-1} \cdot \mathrm{day}^{-1}$ ). The lowest dose $\left(500 \mathrm{mg} \cdot \mathrm{kg}^{-1} \cdot \mathrm{day}^{-1}\right)$ was based on the data obtained in humans recalculated for the rodent model. T-1000 and T-2000 doses were two-fold and fourfold higher than the lowest dose according to the recommendations of the reproductive toxicity trials (19). The drug was administered by oral gavage from PD 2 to PD 10. All treatments and tests were carried out between 8 and 11 am.
Animals were euthanized via diaphragmatic rupture after all in vivo procedures were carried out. The anesthesia protocol included a combination of $90 \mathrm{mg} / \mathrm{kg}$ of a dissociative anesthetic ketamine hydrochloride (Vetanarcol, Konig, Brazil) and $10 \mathrm{mg} / \mathrm{kg}$ of a muscle relaxant xylazine hydrochloride (Kensol, Konig). Both drugs were blended and administered together via the intraperitoneal route. Blood was extracted through cardiac puncture under general anesthesia and centrifuged $\left(4000 \mathrm{~g}, 4^{\circ} \mathrm{C}\right.$, $10 \mathrm{~min})$, and the serum was stored at $-80^{\circ} \mathrm{C}$.

\section{Maternal assessment}

Clinical toxicity and biochemical assays. Piloerection, diarrhea, chromodacryorrhea, and weight gain or loss were recorded during the treatment period. Food and water consumption were also registered during treatment by weighing the amount of offered food and measuring offered water in a graduated cylinder. The differences between this value and the amount remaining $24 \mathrm{~h}$ after food and water were evaluated (20).

Serum aspartate aminotransferase (AST), alanine aminotransferase (ALT), serum creatinine (CRE), and serum urea nitrogen (BUN) were measured by a commercial assay kit on an automatized CobaS c111 (Roche ${ }^{\circledR}$, Switzerland) device.

Milk analysis. Milk samples were obtained on day 10 of lactation, which was the last day of treatment. Mothers were separated from their pups for $2 \mathrm{~h}$ and were injected with oxytocin (5 IU/mL sc; Eurofarm, Brazil). After $30 \mathrm{~min}$, mothers were lightly anesthetized with $10 \mathrm{mg} / \mathrm{kg}$ xylazine $(2 \%)$ and $90 \mathrm{mg} / \mathrm{kg}$ ketamine (5\%), and milk was extracted manually from the thoracic and abdominal teats. All milk samples were analyzed for lactose, total protein, total cholesterol, and triglycerides. Lactose was estimated by a colorimetric method using picric acid. Commercial lactose (Sigma, USA) was used as a standard. Protein was estimated by a colorimetric method using bovine serum albumin (Sigma) as a standard. Total cholesterol and triglycerides were determined by enzymatic and colorimetric methods, respectively, using commercial kits (Bioclin, Brazil).

Maternal behavior. Maternal behavior was observed daily for $50 \mathrm{~min}$ in the housing cages of mothers and litter between PD 1 and PD 10. The time of observation was during the light phase of the light-dark cycle between 8 and $9 \mathrm{am}$. The following types of behavior were observed: nursing posture, licking and grooming, nest organization, and maintenance. For recording, " 1 " was used to indicate that a behavior occurred and " 0 " was used to indicate that a behavior did not occur. The parameters were analyzed according to Slamberová et al. (21).

\section{Offspring assessment}

Physical and motor development assessment. After offspring birth, weight gain was recorded on PD 2, 4, 6, 10, and 25. From PD 2 until the appearance of the variable, 
the female and male offspring were inspected daily for physical development parameters: eye opening, ear unfolding, lanugo appearance, eruption of upper and lower incisor, descent of the testes, and vaginal opening. Neuromotor development tests, including negative geotaxis, postural response, orientation, cliff avoidance, and grasping reflex, were monitored daily. Tests were carried out daily and lasted no longer than $15 \mathrm{~s}$ per trial. The first day with a positive response was recorded for each animal.

Behavioral studies. On PD 60, the elevated plus maze (EPM) test and step-down inhibitory avoidance task were performed in the female and male offspring (one female and one male per litter were randomly selected).

Anxiety was evaluated using the EPM. The apparatus consisted of a cross-like structure with two opposing open arms (OA) and two closed arms surrounded by $30-\mathrm{cm}$ high walls, of the same dimension $(50 \mathrm{~cm}$ long and $10 \mathrm{~cm}$ high). The entry frequency and time spent in the open and closed arms were recorded for $5 \mathrm{~min}$. The anxiety index was calculated according to Cohen et al. (22) as follows: Anxiety Index $=1-$ [([Open arm time / Test duration] + [Open arms entries / Total number of entries]) / 2].

Long-term memory was estimated using the inhibitory avoidance test. The apparatus consisted of a $30 \times 30-\mathrm{cm}$ structure with $50-\mathrm{cm}$ high electronic avoidance response chamber with a platform at a height of $5 \mathrm{~cm}$ with a diameter of $7 \mathrm{~cm}$ at the top surface. The platform was attached to one corner of the chamber providing protection from the electrical pulse. The chamber floor consisted of 2-mm parallel stainless steel bars spaced $0.5 \mathrm{~cm}$ apart.

During the training session, the animal was gently placed on the platform. When the rat stepped down from the platform and touched the grid, a $0.5 \mu \mathrm{A}$ intensity shock was delivered for $2 \mathrm{~s}$. Twenty-four hours after the training session, the rat was tested under the same conditions without electric shock. The latency of stepping down from the platform was recorded automatically with an end-point of $180 \mathrm{~s}$, and the values were used to estimate the retention memory.

\section{Statistical analysis}

First, the Shapiro-Wilk test was applied to verify data normality. The data were then evaluated by one-way ANOVA followed by Dunnett's post hoc test. Two-way ANOVA with repeated measures was applied to certify possible alterations in body weight and food intake along the study period. The significance level of the tests was $P<0.05$. All tests were performed using SPSS v20 (IBM, USA) and GraphPad Prism ${ }^{\circledR} 5.0$ (USA) software.

\section{Results}

\section{Effects of valerian treatment on mothers during postpartum period}

No signs of clinical toxicity were observed in mothers during monitoring throughout the entire treatment period. As shown in Table 1, there were no significant differences in the serum levels of ALT, AST, urea, and creatinine between the groups.

Body weight of the mothers during the postpartum period was similar in all experimental groups and no differences were found in maternal body weight during breastfeeding (Figure 1A). Also, the differences of food intake during the postpartum period were not significant (Figure 1B).

Patterns of nursing posture, licking and grooming, nest organization, and maintenance in the mothers were similar during the treatment period indicating that all mothers used in the experiment expressed maternal behavior.

\section{Milk composition}

After the treatment, the protein content was significantly lower in the T-1000 and T-2000 groups compared to that in the control group. The content of lactose was significantly higher in the T-2000 group (44.32\%) compared to that in the control group. There were no significant differences in the content of cholesterol and triglycerides in milk between the groups (Figure 2).

\section{Offspring development}

Body weight during the postnatal development of the female (Figure 1C) and male (Figure 1D) newborns was

Table 1. Plasma markers of hepatic and kidney injury of Wistar rats treated postpartum with valerian.

\begin{tabular}{lcccc}
\hline Parameters & \multicolumn{3}{c}{ Experimental groups } \\
\cline { 2 - 5 } & Control & Vehicle & T-500 & T-1000 \\
\hline AST (U/L) & $89.64 \pm 8.95$ & $90.60 \pm 10.89$ & $86.31 \pm 18.34$ & $93.31 \pm 12.41$ \\
ALT (U/L) & $70.86 \pm 21.30$ & $70.44 \pm 15.40$ & $63.49 \pm 15.72$ & $61.83 \pm 9.55$ \\
Urea (mg/dL) & $45.67 \pm 9.99$ & $46.10 \pm 10.52$ & $46.06 \pm 8.85$ & $59 \pm 12.68$ \\
Creatinine (mg/dL) & $0.29 \pm 0.07$ & $0.30 \pm 0.04$ & $0.29 \pm 0.05$ & $43.75 \pm 8.47$ \\
\hline
\end{tabular}

Control group: $1 \mathrm{~mL}$ distilled water; Vehicle group: $1 \mathrm{~mL}$ distilled water, $20 \%$ of glycerin; T-500: $500 \mathrm{mg} \cdot \mathrm{kg}^{-1} \cdot \mathrm{day}^{-1}$ of valerian; T-1000: $1000 \mathrm{mg} \cdot \mathrm{kg}^{-1} \cdot \mathrm{day}^{-1}$ of valerian, T-2000: $2000 \mathrm{mg} \cdot \mathrm{kg}^{-1} \cdot \mathrm{day}^{-1}$ of valerian. Data are reported as means \pm SE of 15 animals per group. ALT: alanine aminotransferase $(F(4,70)=0.8709, P=0.1306)$, AST: serum aspartate aminotransferase $(F(3,52)=0.7095, P=0.5492)$, urea $(F(4,69)=0.4813, P=0.9703)$, and creatinine $(F(4,69)=1.399, P=0.8388)$. One-way ANOVA and Dunnett's test. 
A

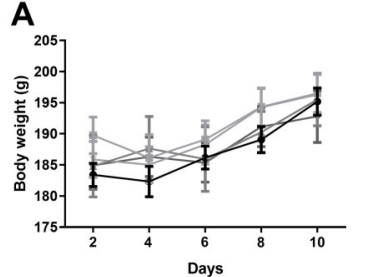

C

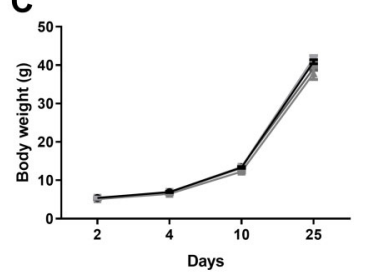

B
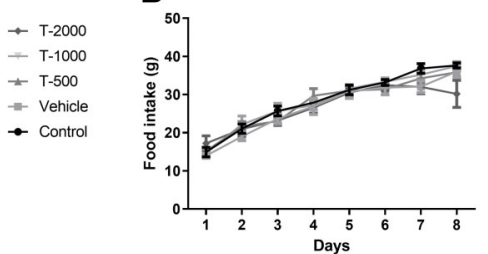

- T-2000

+ T-1000

— T-500

-1-Vehicle

$\rightarrow$ Control

$\rightarrow \mathrm{T}-2000$
$+\mathrm{T}-1000$

$=\mathrm{T}-500$

- Vehicle

- Control

D

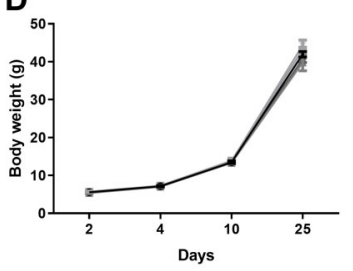

$\rightarrow \mathrm{T}-2000$

- T-1000

$\Rightarrow \mathrm{T}-500$

- Vehicle

$\rightarrow$ Control

Figure 1. Effect of valerian treatment on body weight and food intake of mothers and on body weight of the offspring. Groups: Control (1 mL distilled water), vehicle (1 mL distilled water, $20 \%$ of glycerol), T-500 (500 mg $\cdot \mathrm{kg}^{-1} \cdot \mathrm{day}^{-1}$ of valerian), T-1000 $\left(1000 \mathrm{mg} \cdot \mathrm{kg}^{-1} \cdot \mathrm{day}^{-1}\right.$ of valerian), and T-2000 (2000 mg $\mathrm{kg}^{-1} \cdot \mathrm{day}^{-1}$ of valerian). A, Body weight of mothers $(F(4,347)=1.036, P=0.3885)$. B, Food intake of mothers $(F(4,347)=8.034, P=0.3885)$. C, Body weight of female offspring on postnatal days $2,4,10$, and $25(F(4,262)=6.646, P=0.092)$. $D$, Body weight of male offspring on postnatal days $2,4,10$, and $25(F(4,254)=4.748, P=0.1010)$. Data are reported as means $\pm S E$ of 15 mothers/group and 4 newborns/mother. No significant difference was found among groups (2-way repeated measures ANOVA).
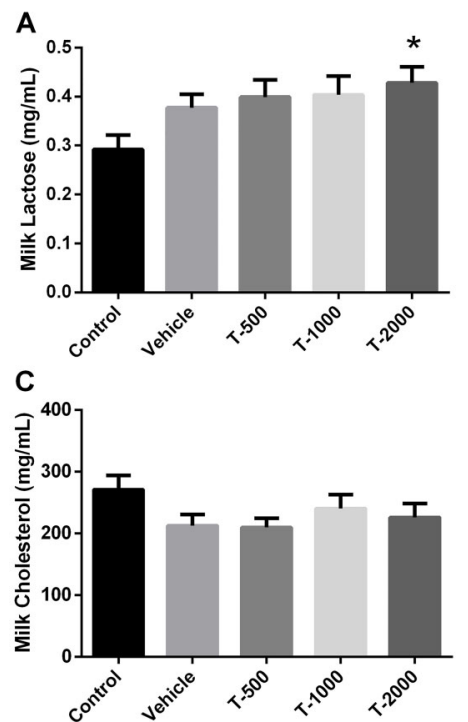

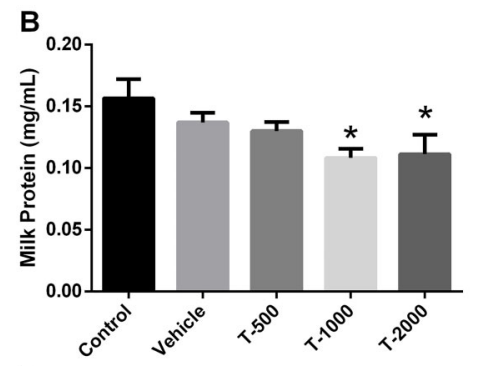

D

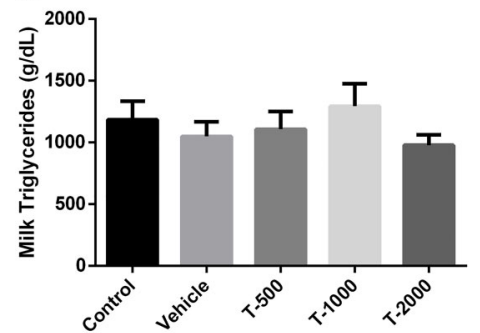

Figure 2. Effect of valerian treatment on milk composition of mothers. Values of $(\mathbf{A})$ lactose $\left(F(4,75)=0.1682,{ }^{*} P=0.048\right)$, (B) total protein $\left(F(4,71)=4.89,{ }^{*} P=0.046\right),(C)$ cholesterol $(F(4,63)=4.833, P=0.195)$, and $(D)$ triglycerides $(F(4,64)=1.775, P=0.564)$ in the control $(1 \mathrm{~mL}$ distilled water), vehicle ( $1 \mathrm{~mL}$ distilled water, $20 \%$ of glycerol), T-500 (500 mg $\mathrm{kg}^{-1} \cdot \mathrm{day}^{-1}$ of valerian), T-1000 (1000 mg. $\mathrm{kg}^{-1} \cdot \mathrm{day}^{-1} \mathrm{of}^{-1}$ valerian), and T-2000 (2000 $\mathrm{mg} \cdot \mathrm{kg}^{-1} \cdot \mathrm{day}^{-1}$ of valerian) groups. ${ }^{*} \mathrm{P}<0.05$ compared to control (one-way ANOVA/Dunnett's test).

not significantly different between the groups. The days of appearance of signs indicative of physical and neuromotor parameters were similar between the experimental groups in the female and male offspring (Tables 2 and 3 ).

\section{Anxiety behavior of adult offspring}

The percentage of time spent in OA, percentage of number of entries into $O A$, and anxiety index are shown in
Figure $3 \mathrm{~A}-\mathrm{F}$ ); the values in both the female and male offspring from valerian-treated mothers were not significantly different from those in the Control and Vehicle groups.

\section{Long-term memory of adult offspring}

The latency of descent from the platform in the female offspring (Figure 4A) was significantly shorter (by $69.49 \%$ ) 
Table 2. Day of appearance of the physical development signs analyzed in the groups.

\begin{tabular}{|c|c|c|c|c|c|c|}
\hline \multirow[t]{2}{*}{ Physical parameters } & \multirow[t]{2}{*}{ Gender } & \multicolumn{5}{|c|}{ Experimental groups } \\
\hline & & Control & Vehicle & $\mathrm{T}-500$ & $\mathrm{~T}-1000$ & T-2000 \\
\hline \multirow[t]{2}{*}{ Lanugo } & Male & $3.26 \pm 0.56$ & $2.98 \pm 0.48$ & $3.04 \pm 0.41$ & $2.88 \pm 0.36$ & $2.98 \pm 0.44$ \\
\hline & Female & $3.24 \pm 0.54$ & $3.10 \pm 0.56$ & $3.16 \pm 0.49$ & $2.98 \pm 0.44$ & $3.05 \pm 0.61$ \\
\hline \multirow[t]{2}{*}{ Ear unfolding } & Male & $4.71 \pm 0.47$ & $4.65 \pm 0.40$ & $4.71 \pm 0.66$ & $4.53 \pm 0.60$ & $4.75 \pm 0.36$ \\
\hline & Female & $4.69 \pm 0.49$ & $4.76 \pm 0.35$ & $4.70 \pm 0.71$ & $4.54 \pm 0.67$ & $4.73 \pm 0.45$ \\
\hline \multirow[t]{2}{*}{ Hair } & Male & $8.28 \pm 0.90$ & $8.14 \pm 0.84$ & $8.01 \pm 0.96$ & $7.95 \pm 0.44$ & $8.31 \pm 0.77$ \\
\hline & Female & $8.31 \pm 0.98$ & $8.48 \pm 1.22$ & $8.46 \pm 0.90$ & $7.98 \pm 0.71$ & $8.23 \pm 0.78$ \\
\hline \multirow[t]{2}{*}{ Superior incisor eruption } & Male & $7.91 \pm 0.71$ & $8.56 \pm 1.19$ & $8.67 \pm 1.06$ & $8.41 \pm 1.01$ & $8.69 \pm 1.09$ \\
\hline & Female & $7.94 \pm 0.64$ & $8.44 \pm 1.00$ & $8.66 \pm 0.93$ & $8.41 \pm 1.04$ & $8.92 \pm 1.12$ \\
\hline \multirow[t]{2}{*}{ Inferior incisor eruption } & Male & $10.08 \pm 0.66$ & $10.21 \pm 0.68$ & $10.31 \pm 0.85$ & $10.03 \pm 0.74$ & $10.35 \pm 0.81$ \\
\hline & Female & $10.08 \pm 0.87$ & $10.08 \pm 0.75$ & $11.45 \pm 1.90$ & $10.31 \pm 0.79$ & $10.42 \pm 2.29$ \\
\hline \multirow[t]{2}{*}{ Eye opening } & Male & $16.81 \pm 0.81$ & $16.80 \pm 0.58$ & $16.96 \pm 0.59$ & $16.54 \pm 0.61$ & $16.73 \pm 0.69$ \\
\hline & Female & $16.70 \pm 0.78$ & $16.62 \pm 0.66$ & $16.79 \pm 0.68$ & $16.57 \pm 0.70$ & $16.69 \pm 0.53$ \\
\hline Testis descent & Male & $21.99 \pm 1.20$ & $21.73 \pm 1.76$ & $22.95 \pm 1.86$ & $22.31 \pm 1.89$ & $21.56 \pm 2.09$ \\
\hline Vaginal opening & Female & $35.17 \pm 2.21$ & $34.21 \pm 1.81$ & $34.75 \pm 3.31$ & $34.71 \pm 1.67$ & $34.19 \pm 2.06$ \\
\hline
\end{tabular}

Control group: $1 \mathrm{~mL}$ distilled water; Vehicle group: $1 \mathrm{~mL}$ distilled water, $20 \%$ of glycerin; T-500: $500 \mathrm{mg} \cdot \mathrm{kg}^{-1} \cdot \mathrm{day}^{-1}$ of valerian; T-1000: $1000 \mathrm{mg} \cdot \mathrm{kg}^{-1} \cdot \mathrm{day}^{-1}$ of valerian; T-2000: $2000 \mathrm{mg} \cdot \mathrm{kg}^{-1} \cdot \mathrm{day}^{-1}$ of valerian. Data are reported as means \pm SE of 15 animals per group. The differences among groups were not significant (one-way ANOVA and Dunnett's test). Lanugo: Male $(F(4,70)=0.8542, P=0.2378)$, Female $(F(4,68)=0,5254, P=0.7174)$; Ear Unfolding: Male $(F(4,70)=0.3577, P=0.8029)$, Female $(F(4,70)=0.3524, P=0.8415)$; Hair: Male $(F(4,70)=1.183, P=0.6879)$, Female $(F(4,70)=0.7391, P=0.5921)$; Superior Incisor Eruption: Male $(F(4,69)=0.6426, P=0.2331)$, Female $(F(4,70)=0.7661, P=0.0924)$; Inferior Incisor Eruption: Male $(F(4,68)=0.6720, P=0.7387)$, Female $(F(4,70)=0.8084, P=0.4354)$; Eye Opening: Male $(F(4,57)=0.4163, P=0.6505)$, Female $(F(4,58)=0.3915, P=0.9122)$.

Table 3. Day of appearance of the neuromotor development signs analyzed in the groups.

\begin{tabular}{|c|c|c|c|c|c|c|}
\hline \multirow[t]{2}{*}{ Reflex parameters } & \multirow[t]{2}{*}{ Gender } & \multicolumn{5}{|c|}{ Experimental groups } \\
\hline & & Control & Vehicle & $\mathrm{T}-500$ & T-1000 & T-2000 \\
\hline \multirow[t]{2}{*}{ Grasping reflex } & Male & $2.06 \pm 0.18$ & $2.00 \pm 0.00$ & $2.00 \pm 0.00$ & $2.01 \pm 0.06$ & $2.01 \pm 0.06$ \\
\hline & Female & $2.01 \pm 0.06$ & $2.00 \pm 0.00$ & $2.01 \pm 0.06$ & $2.03 \pm 0.12$ & $2.00 \pm 0.00$ \\
\hline \multirow[t]{2}{*}{ Righting reflex } & Male & $2.15 \pm 0.23$ & $2.13 \pm 0.26$ & $2.33 \pm 0.65$ & $2.28 \pm 0.46$ & $2.31 \pm 0.55$ \\
\hline & Female & $2.16 \pm 0.27$ & $2.25 \pm 0.41$ & $2.53 \pm 0.65$ & $2.36 \pm 0.58$ & $2.47 \pm 0.68$ \\
\hline \multirow[t]{2}{*}{ Cliff avoidance } & Male & $8.20 \pm 1.62$ & $8.75 \pm 1.70$ & $8.86 \pm 1.28$ & $8.18 \pm 1.42$ & $8.30 \pm 1.52$ \\
\hline & Female & $7.60 \pm 0.93$ & $7.67 \pm 1.52$ & $8.09 \pm 1.19$ & $8.48 \pm 1.70$ & $7.92 \pm 1.06$ \\
\hline \multirow[t]{2}{*}{ Negative geotaxis } & Male & $7.05 \pm 1.80$ & $7.15 \pm 1.50$ & $6.64 \pm 1.31$ & $6.81 \pm 1.34$ & $7.30 \pm 1.26$ \\
\hline & Female & $7.00 \pm 1.28$ & $7.33 \pm 1.35$ & $6.84 \pm 1.19$ & $6.81 \pm 1.39$ & $7.40 \pm 1.01$ \\
\hline
\end{tabular}

Control group: $1 \mathrm{~mL}$ distilled water; Vehicle group: $1 \mathrm{~mL}$ distilled water, $20 \%$ of glycerin; T-500: $500 \mathrm{mg} \cdot \mathrm{kg}^{-1} \cdot \mathrm{day}^{-1}$ of valerian; T-1000: $1000 \mathrm{mg} \cdot \mathrm{kg}^{-1} \cdot \mathrm{day}^{-1}$ of valerian, T-2000: $2000 \mathrm{mg} \cdot \mathrm{kg}^{-1} \cdot$ day $^{-1}$ of valerian. Data are reported as means \pm SE of 15 animals per group. The differences among groups were not significant (one-way ANOVA and Dunnett's test). Grasping reflex: Male $(F(4,70)=1.299, P=0.2789)$, Female $(F(4,70)=0.5833, P=0.6757)$; Righting reflex: Male $(F(4,70)=0.6120, P=0.6554)$, Female $(F(4,70)=0.8655, P=0.3203)$; Cliff avoidance: Male $(F(4,69)=0.4236, P=0.6091)$, Female $(F(4,68)=1.570, P=0.3605)$; Negative geotaxis: Male $(F(4,70)=0.8792$, $\mathrm{P}=0.7442)$, Female $(\mathrm{F}(4,69)=0.5593, \mathrm{P}=0.5494)$.

in the T-1000 group $(\mathrm{P}<0.01)$. Despite no statistical difference, the mean latency values of the other groups were: Vehicle $(-21.87 \%)$, T-500 $(-56.31 \%)$, and T-2000 $(-42.35 \%)$.

In the male offspring, the latency of descent from the platform (Figure 4B) was: Vehicle $(-1.28 \%)$, T-500 $(-3.86 \%), \mathrm{T}-1000(-47.72 \%)$, and T-2000 (-17.19); however, the differences were not statistically significant $(P=0.4747)$.

\section{Discussion}

The lack of clinical and biochemical toxicity in mothers treated with valerian in this study was in agreement with other reports in the literature on this experimental model (11). No signs of systemic toxicity were observed in mature female or male offspring after valerian treatment during pregnancy. Serum levels of AST and ALT in the mothers indicated that liver function was not affected by 
A

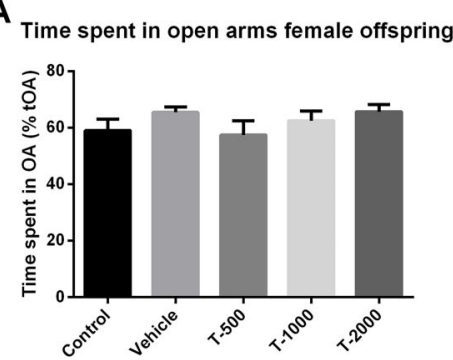

C

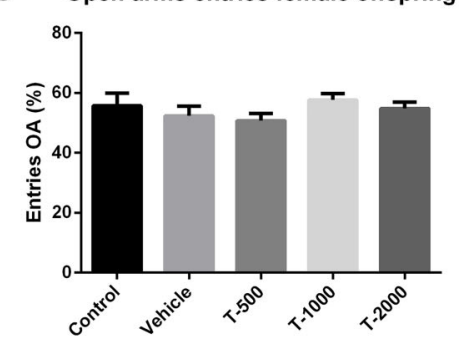

E

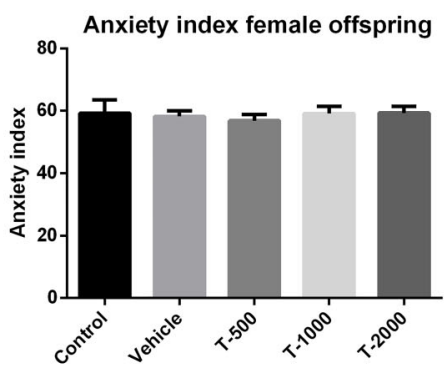

B

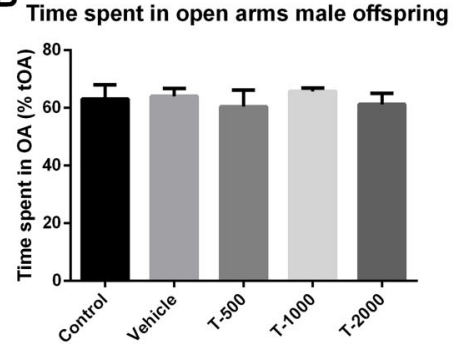

D

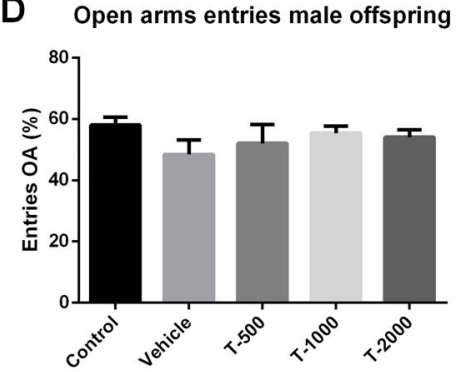

$F$

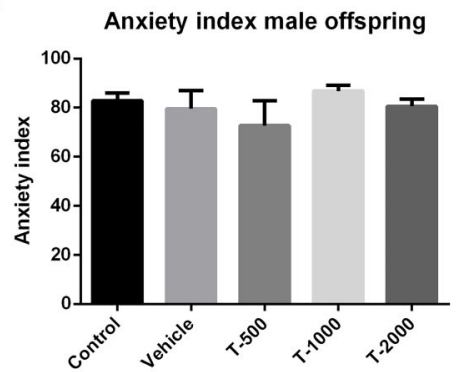

Figure 3. Anxiety-like behavior in adult offspring of mothers treated with valerian during the postpartum period. Groups: Control (1 mL distilled water), Vehicle (1 mL distilled water, $20 \%$ of glycerol), T-500 (500 mg $\mathrm{kg}^{-1} \cdot \mathrm{day}^{-1}$ of valerian), T-1000 (1000 mg $\cdot \mathrm{kg}^{-1} \cdot \mathrm{day}^{-1}$ of valerian), and T-2000 (2000 mg $\mathrm{kg}^{-1} \cdot \mathrm{day}^{-1}$ of valerian). $\mathbf{A}, \mathbf{C}$, and $\mathbf{E}$, percentage of time spent in the open arms $(F(2,072,18,65)=1.579$, $P=0.2325)$, percentage of number of entries $(F(4,53)=0.6700, P=0.4672)$, and anxiety index $(F(4,50)=1.357, P=0.9670)$ of female offspring. B, D, and $F$ percentage of time spent in the open arms $(F(2.031,18.28)=0.2641, P=0.7740)$, percentage of number of entries $(F(4,48)=1.963,0.4912)$, and anxiety index $(F(4,41)=0.9466, P=0.6230)$ of male offspring. Data are reported as means $\pm S E$. ( $n=8-13$ per group). Values in the groups were normalized to those in the control group. One-way ANOVA and Dunnett's test.

valerian treatment during lactation, and creatinine and urea levels indicated normal kidney function in the treatment model.

The use of medications during lactation requires special attention because drug substances may be excreted into the milk, which is essential for newborn development, thus altering milk composition (23). In the present study, significant differences were found between the control and T-1000 and T-2000 groups (reduction in total protein) and between the control and T-2000 (increase of lactose) experimental groups, indicating that high doses of valerian significantly altered these important components. Alterations in macronutrients, such as protein and lactose, are related to altered functions in several regulatory systems of infants (24). Protein from breast milk provides indispensable amino acids, necessary for new protein synthesis during growth, and also performs immunological, enzymatic, absorptive, and defense functions against pathogens, in addition to nutrition $(24,25)$. In contrast to protein, the lactose content is generally more stable and is important for maintaining the osmotic pressure of breast milk (26). In this study, lactose content was increased in the T-2000 treatment, which may be related to a reduction in protein content, since lactose levels negatively correlate with protein content as lactation is established (27). The effects of increased lactose on the newborn are not known. However, since this carbohydrate accounts for about $40 \%$ of the total energy of breast milk (28) it can be 

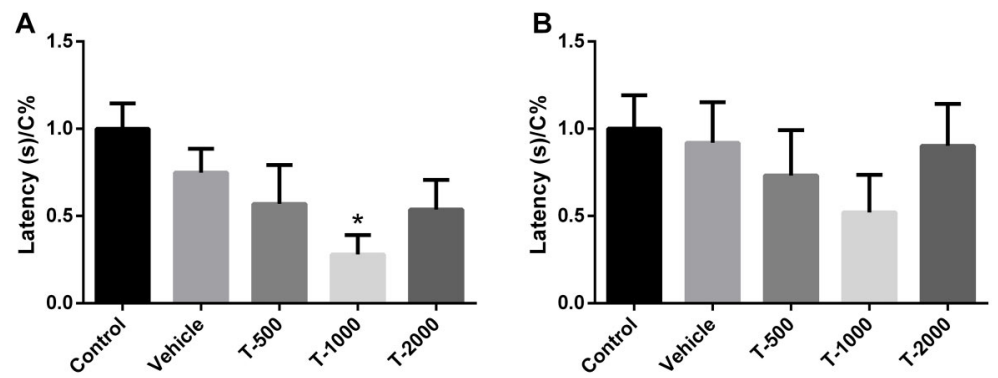

Figure 4. Long-term memory in adult offspring of mothers treated with valerian in the postpartum period. Groups: Control (1 mL distilled water), Vehicle group (1 mL distilled water, $20 \%$ of glycerol), T-500 (500 mg $\cdot \mathrm{kg}^{-1} \cdot \mathrm{day}^{-1}$ of valerian), T-1000 (1000 mg $\mathrm{kg}^{-1} \cdot \mathrm{day}^{-1}$ of valerian), and T-2000 (2000 $\mathrm{mg} \cdot \mathrm{kg}^{-1} \cdot \mathrm{day}^{-1}$ of valerian). A, Female offspring, latency time (s) performing the step-down inhibitory avoidance task $\left(F(4,5)=0.1603,{ }^{*} P<0.01\right.$, compared to control). (B) Male offspring, latency time (s) performing the step down inhibitory avoidance task $(F(4,5)=1.172, P=0.4747)$. Data are reported as means $\pm S E(n=8-13$ per group). Values in the groups were normalized to those in the control group. One-way ANOVA and Dunnett's test.

assumed that the milk of the group T-2000 had a relatively higher caloric content, being an extra source of energy for offspring, but not enough to change the nutritional status. This is the first study to assess breast milk composition after maternal treatment with valerian; our results emphasized the importance of evaluating the excretion of drug substances in milk and possible alterations of milk components. Thus, further studies are needed to determine the possible relationship between these findings and the observed effects on offspring. According to the National Library of Medicine (USA) (2018) and based on our extensive literature review, there are no previous data on the safety and efficacy of valerian in nursing mothers or infants; therefore, these data may be considered the greatest strength of our study.

Behavioral patterns of mothers during lactation are essential to ensure the development of healthy offspring (29). However, the use of a substance that acts on the CNS may disrupt normal behavior $(30,31)$. Evidence has shown that important interactions between the neonate and mother are predictive of offspring emotional behavior and neuroendocrine profiles later in life $(29,32)$. Licking and grooming frequencies represent the main source of tactile stimulation for newborns, and a decrease in these stimuli may affect offspring brain development through reprogramming mechanisms $(33,34)$. Licking and grooming and other maternal behaviors monitored during the entire treatment period were not statistically different between experimental groups indicating that the offspring of treated mothers received adequate developmental stimuli.

No alterations in the physical postnatal development were observed. Body weight evolution was similar in all experimental groups indicating that adequate breastfeeding occurred despite alterations of milk components, and this conclusion was in agreement with the results of maternal behavior monitoring. The physical contact between mothers and pups also ensured similar offspring development of the groups. The same considerations apply for reflex development, which is sensitive in the postnatal period considering the process of brain maturation. Studies evaluating the consequences of benzodiazepine treatment in rats during pregnancy reported delays in the development of neonatal reflexes (35). Previous findings indicate that valerian treatment during pregnancy does not cause alterations in the physical or neuromotor development of the offspring (11).

Based on the results of the present study, anxiety behavior was not observed in the offspring of treated mothers. Female offspring of the T-1000 group submitted to stepdown inhibitory avoidance test in adulthood showed significant memory impairment. A single shock stimulation is sufficient to create robust long-term memory making this task highly suitable to investigate the drug effects on memory. Apparently, maternal treatment leads to certain consequences in the offspring by influencing brain regions responsible for this type of memory, such as the hippocampus (36). Figure 4 shows a U-shaped dose-response curve, which can be related to an overcompensation in response to a disruption in homeostasis promoting different biological effects from the T-1000 treatment, commonly observed in toxicological and pharmacological studies (37). However, the $\mathrm{T}-1000$ and T-2000 doses adjusted to rodent metabolism are higher compared to the doses usually used in humans, which we consider a limitation of this study. Future studies should consider different doses used in scientific studies and conduct tests to identify a dose closest to that used in humans, taking into account the specific differences between experimental models. The mechanisms mediating sex-specific effects are poorly understood; however, different phenotypes may manifest depending on the sex of the fetus or newborn (38).

\section{Conclusions}

Our study showed that high doses of valerian altered the milk composition and the memory of offspring while the lowest dose, closest to that used in humans, did not cause adverse effects and was safe with respect to the parameters evaluated. This underscores the importance 
of self-medication issues and the misconception that herbal supplements are not harmful (39).

Further studies are required to determine the sexspecific responses to this treatment, identify the mechanisms related to memory impairment, and determine the consequences of changes in milk composition.

\section{References}

1. Meltzer-Brody S, Howard LM, Bergink V, Vigod S, Jones I, Munk-Oslen T, et al. Postpartum psychiatric disorders. Nat Rev Dis Primers 2018; 4: 18022, doi: 10.1038/nrdp.2018.22.

2. Ross LE, McLean LM. Anxiety disorders during pregnancy and the postpartum period: a systematic review. J Clin Psychiatry 2006; 67: 1285-1298, doi: 10.4088/JCP.v67n0818.

3. Rees S, Channon S, Waters CS. The impact of maternal prenatal and postnatal anxiety on children's emotional problems: a systematic review. Eur Child Adolesc Psychiatry 2019; 28: 257-280, doi: 10.1007/s00787-018-1173-5.

4. Barker DJP. The developmental origins of adult disease. Eur J Epidemiol 2003; 18: 733-736, doi: 10.1023/A:102538890 1248.

5. Gluckman PD, Hanson MA, Buklijas T. A conceptual framework for the developmental origins of health and disease. J Dev Orig Health Dis 2010; 1: 6-18, doi: 10.1017/ S2040174409990171.

6. Kessler RC, Soukup J, Davis RB, Foster DF, Wilkey SA, Van Rompani Ml, et al. The use of complementary and alternative therapies to treat anxiety and depression in the United States. Am J Psychiatry 2001; 158: 289-294, doi: 10.1176/appi.ajp.158.2.289.

7. Hadley S, Petry JJ. Valerian. Am Fam Physician 2003; 67: 1755-1758.

8. Patočka $P$, Jakl J. Biomedically relevant chemical constituents of Valeriana officinalis. J Appl Biomed 2010; 8: 11-18, doi: 10.2478/v10136-009-0002-z.

9. Houghton PJ. The scientific basis for the reputed activity of Valerian. J Pharm Pharmacol 1999; 511: 505-512, doi: 10.1211/0022357991772772.

10. Hattesohl M, Feistel B, Hartwig S, Lehnfeld R, Hegger M, Winterhoff $\mathrm{H}$, et al. Extracts of Valeriana officinalis L. s.I. show anxiolytic and antidepressant effects but neither sedative nor myorelaxant properties. Phytomedicine 2008; 15: 2-15, doi: 10.1016/j.phymed.2007.11.027.

11. Campos ML, Mourao-Junior CA, Sá RCS, Brandão MAF and Guerra MO. Physical and neurobehavioral development of rat offspring after maternal exposure to Valeriana officinalis during gestation. J Med Plants Res 2014; 26: 928-935, doi: $10.5897 / J M P R$.

12. Yoo DY, Jung HY, Nam SM, Kim JW, Choi JH, Kawak YG, et al. Valeriana officinalis extracts ameliorate neuronal damage by suppressing lipid peroxidation in the gerbil hippocampus following transient cerebral ischemia. $J$ Med Food 2015; 18: 642-647, doi: 10.1089/jmf.2014.3295.

13. Malva JO, Santos S, Macedo T. Neuroprotective properties of Valeriana officinalis extracts. Neurotox Res 2004; 6: 131140, doi: 10.1007/BF03033215.

14. Del Valle-Mojica LM, Cordero-Hernández JM, GonzálezMedina G, Ramos-Vélez I, Berríos-Cartagena N, Torres-

\section{Acknowledgments}

This work was supported by the UFJF's Reproductive Biology Centre and by FAPEMIG - Minas Gerais Network of Pharmacologic and Toxicologic Tests of Therapeutic Products.

Hernández BA, et al. Aqueous and ehanolic Valeriana officinalis extracts change the binding of ligands to glutamate receptors. Evid Based Complement Alternat Med 2011; 2011: 891819.

15. Jung HY, Yoo DY, Kim W, Nam SM, Kim JW, Choi JH, et al. Valeriana officinalis root extract suppresses physical stress by electric shock and psychological stress by nociceptive stimulation-evoked responses by decreasing the ratio of monoamine neurotransmitters to their metabolites. BMC Complement Altern Med 2014: 14; 476.

16. Mineo L, Concerto C, Patel D, Mayorga T, Paula M, Chusid $\mathrm{E}$, et al. Valeriana officinalis root extract modulates cortical excitatory circuits in humans. Neuropsychobiology 2017; 75: 46-51, doi: 10.1159/000480053.

17. Murrin LC, Sanders JD, Bylund DB. Comparison of the maturation of the adrenergic and serotonergic neurotransmitter systems in the brain: implications for differential drug effects on juveniles and adults. Biochem Pharmacol 2007; 73: 1225-1236, doi: 10.1016/j.bcp.2007.01.028.

18. Amer MR, Cipriano GC, Venci JV, Gandhi MA. Safety of popular herbal supplements in lactating women. J Hum Lact 2015; 31: 348-353, doi: 10.1177/0890334415580580.

19. Al-Majed AA, Al-Yahya AA, Al-Bekairi AM, Al-Shabanah OA, Qureshi S. Studies on the cytological and biochemical effects of valerian in somatic and germ cells of Swiss albino mice. Food Chem Toxicol 2006; 44: 1830-1837, doi: 10.1016/j.fct.2006.06.001.

20. Christian M. Test methods for assessing female reproductive and developmental toxicology, in principles and methods of toxicology. In: Philadelphia: W.H.T. Francis; 2001. p 1641-1711.

21. Slamberová $R$, Charousová $P$, Pometlová M. Maternal behavior is impaired by methamphetamine administered during pre-mating, gestation and lactation. Reprod Toxicol 2005; 20: 103-110, doi: 10.1016/j.reprotox.2004.11.010.

22. Cohen H, Matar M, Joseph Z. Animal models of posttraumatic stress disorder. Curr Protoc Neurosci 2013; 9.45, doi: 10.1002/0471142301.ns0945s64.

23. Ito S. Mother and child: medication use in pregnancy and lactation. Clin Pharmacol Ther 2016; 100: 8-11, doi: 10. 1002/cpt.383.

24. Martin CR, Ling PR, Blackburn GL. Review of infant feeding: key features of breast milk and infant formula. Nutrients 2016; 8: 279, doi: 10.3390/nu8050279.

25. Lönnerdal B. Effects of maternal dietary intake on human milk composition. J Nutr 1986; 116: 499-513, doi: 10.1093/ jn/116.4.499.

26. Thurl S, Henker J, Taut H, Sawatzki G. Variations of neutral oligosaccharides and lactose in human milk during the feeding. Z Ernahrungswiss 1993; 32: 262-269, doi: 10.1007/ BF01611164. 
27. Kulski JK, Hartmann PE. Changes in human milk composition during the initiation of lactation. Aust J Exp Biol Med Sci 1981; 59: 101-114, doi: 10.1038/icb.1981.6.

28. Hasckhe F, Haiden N, Thakkar SK. Nutritive and bioactive proteins in breastmilk. Ann Nutr Metab 2016; 69: 17-26, doi: $10.1159 / 000452820$.

29. Champagne FA, Francis DD, Mar A, Meaney MJ. Variations in maternal care in the rat as a mediating influence for the effects of environment on development. Physiol Behav 2003; 79: 359-371, doi: 10.1016/S0031-9384(03)00149-5.

30. Panes $A$, Fourrier-Réglat $A$, Verdoux $H$, Tournier $M$. Use and misuse of benzodiazepines in patients with psychiatric disorders [in French]. Presse Med 2018; 47: 886-891, doi: 10.1016/j.lpm.2018.10.003.

31. Stewart SA. The effects of benzodiazepines on cognition. J Clin Psychiatry 2005; 66: 9-13, doi: 10.4088/JCP.v66n0709.

32. Peña CJ, Champagne FA. Implications of temporal variation in maternal care for the prediction of neurobiological and behavioral outcomes in offspring. Behav Neurosci 2013; 127: 33-46, doi: 10.1037/a0031219.

33. Kaffman A, Meaney MJ. Neurodevelopmental sequelae of postnatal maternal care in rodents: clinical and research implications of molecular insights. $J$ Child Psychol
Psychiatry 2007; 48: 224-244, doi: 10.1111/j.1469-7610. 2007.01730.x.

34. Fish EW, Shahrokh D, Bagot R, Caldji C, Bredy T, Szyf M, et al. Epigenetic programming of stress responses through variations in maternal care. Ann NY Acad Sci 2004; 1036: 167-180, doi: 10.1196/annals.1330.011.

35. Nicosia A, Giardina L, Di Leo F, Medico M, Mazzola C, Genazzani AA, et al. Long-lasting behavioral changes induced by pre- or neonatal exposure to diazepam in rats. Eur J Pharmacol 2003; 469: 103-109, doi: 10.1016/S00142999(03)01729-1.

36. Roozendaal B, McGaugh JL. Memory modulation. Behav Neurosci 2011; 125: 797-824, doi: 10.1037/a0026187.

37. Calabrese E, Baldwin LA. U-shaped dose-responses in biology, toxicology, and public health. Annu Rev Public Health 2001; 22: 15-33, doi: 10.1146/annurev.publhealth. 22.1.15.

38. Gifford RM, Reynolds RM. Sex differences in early-life programming of the hypothalamic-pituitary-adrenal axis in humans. Early Hum Dev 2017; 114: 7-10, doi: 10.1016/ j.earlhumdev.2017.09.011.

39. Dog TL. The use of botanicals during pregnancy and lactation. Altern Ther Health Med 2009; 15: 54-58. 